\title{
LA DIVINIDAD KUKULCÁN Y SU RELACIÓN CON LA gUerRa EN CHICHÉN Itzá, PENÍNSULA de yucatán, MÉXICO
}

Alexandre Guida Navarro'

Resumen: Este artículo tiene como objetivo presentar algunas evidencias materiales de la existencia de un culto guerrero enfocado en un personaje conocido en la arqueología de Yucatán: Kukulcán. Primeramente discutimos algunos conceptos sobre este dios, luego tratamos del tema del espacio sagrado, y por fin presentamos como se manifiesta la divinidad en el registro arqueológico de Chichén Itzá.

Palabras-clave: Cultura Material; Espacio Sagrado; Guerra; Área Maya; Arquitectura.

Abstract: This article aims to present some material evidences of the existence of a warlike cult focused on personage known in the Yucatán archaeology: Kukulcán. Firstly, we discuses about this god, then we treat the sacred space's theme, and we finalize this text showing the divinity manifest yourself on the archaeological vestiges of Chichén Itzá.

Keywords: Material Culture, Sacred Space, Warfare; Maya Area, Architecture.

\section{1 - LA ETIMOLOGÍA DE LA PALABRA KUKULCÁN}

Kukulcán fue una importante divinidad de los mayas. Estaba asociado a diversas manifestaciones culturales, donde se destacan el poder político, la guerra y la a religión. Su principal desdoblamiento o manifestación de da bajo la representación de una "serpiente emplumada", que es símbolo de la vida por excelencia, pues asocia el cielo (representado por el ave quetzal) y la tierra (representado por la serpiente) como los generadores de la misma vida (figura 1).

' Doutor em Antropologia pela Universidad Nacional Autónoma de Mexico (UNAM). Professor da Universidade Federal do Maranhão.E-mail: altardesacrificios@yahoo.com.br 


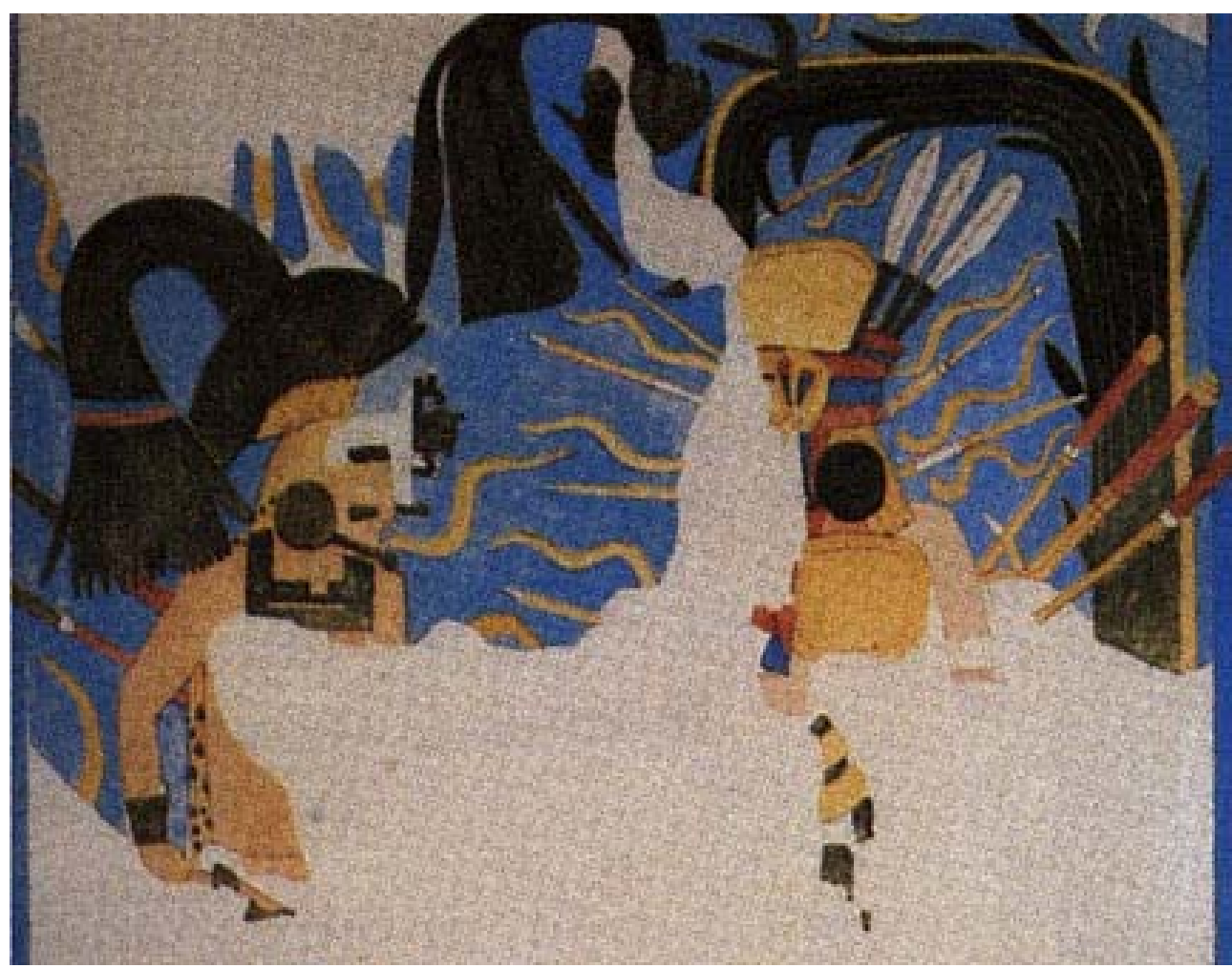

FIGURA I. La divinidad Kukulcán aparece en el lado derecho de la imagen. Por su detrás aparece la serpiente emplumada. Templo superior de los Jaguares, Chichén Itzá. Fotografía tomada por el autor.

Investigamos tres diccionarios de la lengua maya para entender con mayor claridad sus acepciones y relaciones con el personaje así nombrado. En el Calepino de Motul, organizado por Ramón Arzápalo Marín, encontramos las siguientes palabras o combinaciones: a la partícula $k u$ se le da el siguiente significado:

Dios. yotochku. la iglesia \& u canantech ku dios te guarde \& ku ventex a ba ti. encomendaos a dios $\&$ de. ku por dios sale. Ku uinic hombre de dios hombre divino. \& ku uinic buthan balaan ti Dios hombre divino lleno todo de dios \& Item Ku uinic dios hombre. 1 . hombre dios. ${ }^{2}$

Una partícula asociada es kuu, que significa "nido de ave \& u kuu cuic nido de las ardillas que son como lo de los pájaros \& u kuu u bech de las cordonizes hacerlo en el suelo \& u kuu thul cama de los conejos". ${ }^{3}$ La palabra kuk tiene que ver con "renuevo tallo o pimpollo del árbol o breton de berça \& de aquí solo toma por los hijos y descendientes que uno deja \& ante in kuk yumile auydad señor y favoreced a mis hijos y descendientes”. Otro término que hallamos es kul, que significa "lo mismo que ah kukel u kul batab indio a quien el cacique 
manda cosas de gobierno de pueblo y de quien anda siempre acompañado y servido”. Kuul es:

Dios o ydolo in yumile in Kuuile Dominus deus et deus meus. cosa divina ya ti uol in çipci ta kuuk tepal yumile. diose pesame señor dios de aver ofendido a tu divina magestad \& kuul abilah don divino \& De aquí salen Khulna. yglesia cosa de dios o divina \& kuul nok ornamentos de yglesia ropas divinas para el servicio de dios ". Kukum es "pluma de ave en general. ${ }^{4}$

Con relación a la partícula caan, encontramos el significado "cielo". Por su parte, can significa "culebra, nombre genérico. Dadiva, o presente que se da al juez por vía de sobrino, darla o presentarla assi \& yan ua a kamil u can ah kat justicia tech, por ventura has reicevido presente de los que te piden justicia”. El término kan tiene que ver con "piedras que servían a los indios de moneda y de adorno el cuello, maizes y frosoles sazonados". ${ }^{5}$

En el Diccionario Cakchiquel-Español, recopilado por Carmelo Sáenz de Santa María, ${ }^{6}$ en la página 231 encontramos que K’uk' es "quetzal, perica, guacamaya, plumas verdes con que bailan”. En la misma página, Kukum es “pluma de ave general”. Parece ser que en los diccionarios, la palabra Kuk es la raíz del término Kukum.

Con respecto al Diccionario maya Cordemex, organizado por Alfredo Barrera Vázquez, ${ }^{7}$ es ahí donde encontramos más acepciones para los términos que forman la palabra Kukulcan. La palabra k’ul significa:

adoración, reverencia; cierto oficial de la república menores que los ah Duch kabes y mayores que los tupiles; abogado medianero y tercero entre algunos; la rabadilla del ave donde le hacen las plumas de la cola; fruta empedernida, se dice de las frutas que aunque estén muy maduras no se abandonan o tienen partes duras; adorar algún dios, que ha sido o debe ser adorado o reverenciado como dios; cosa divina, don divino. ${ }^{8}$

La partícula Kuk' se asocia a “renuevo, tallo o pimpollo de árbol o bretón de berza, de aquí se toma por los hijos y descendientes que uno deja, tallo de yerba, rama, vástago nuevo, yema o retoño de planta o árbol, brote de plantas”. Sin embargo, la partícula K'uk' tiene que ver con "quetzal, descendencia”. Ya K'u'uk' es "traza del edificio, plumas verdes y muy galanas y grandes que sacan en los bailes". ${ }^{9}$ El término $k$ 'an se asocia a "piedra preciosa, conchas amarillas, cosa amarilla, color amarillo, red de pescadores o de cazadores y pescarán, andanzas, trabajo u ocupaciones varias. ${ }^{10}$ K'uk'um es "pluma de ave en general”. K'u'uk'um es "pluma de ave” y K'uk'um significa “el quetzal, el emplumado por excelencia". ${ }^{11}$ En el mismo diccionario encontramos algunas palabras que tienen 
una relación más intrínseca con la serpiente emplumada. Encontramos que K'uk'ilkan significa "serpiente, serpiente con plumas preciosas” у K'uk'ulkan significa "serpiente emplumada". ${ }^{12}$

Con todo lo anterior nos gustaría hacer un paréntesis acerca de la relación entre el personaje Kukulcán y la serpiente emplumada. En el artículo de Charles Lincoln intitulado "Structural and Philological Evidence for Divine Kinship at Chichén Itzá, Yucatán, México” publicado en 1994, al tratar sobre Kukulcán el autor se preocupa en desmitificar lo que según él no tiene que ver con la serpiente emplumada, o más bien tiene un significado más metafísico. ${ }^{13}$ Después de analizar la filología de la palabra concluye que la palabra Kukulcán tiene que ver más con regeneración vegetativa, y por analogía, con la reproducción humana vista desde una perspectiva de linaje, ya que la mayoría de las acepciones encontradas en el Diccionario Motul hace referencia a fenómenos vegetativos.

Utilizando el Diccionario Motul, uno de los significados de la palabra can, y que los autores la relacionamos con "serpiente", en verdad sería una "tangled bramble”, es decir, “una enredadera herbácea”. ${ }^{14} \mathrm{El}$ autor no ve en la filología de la palabra Kukulcán una asociación con la serpiente emplumada. Así que propone su desuso y abandono, y plantea que deba ser leída como "vegetación que brota o germina” y metafóricamente "línea sanguínea ramificada”. Sin embargo, en el mismo diccionario que le sirve de fuente, Lincoln descarta algunos términos que si se relacionan con la serpiente emplumada, como kukum, que origina la palabra kuk, y que significa "pluma de ave general"; y can, que también puede ser leído como "serpiente, culebra”.

Pensamos que la propuesta de Lincoln es demasiado radical ya que sí encontramos referencia directa de la filología de la palabra Kukulcán asociada a la serpiente emplumada, tanto en el Diccionario Motul, como en el Diccionario Cordemex. Además, no podemos negar la asociación que hicieron los cronistas con respecto a este tema. Como veremos más adelante, todos los cronistas que escribieron sobre Kukulcán, o solamente hicieron una breve referencia a éste, lo relacionan con la serpiente emplumada.

\section{EL PERSONAJE KUKULCÁN}

Poco sabemos acerca de este personaje que fue citado en algunas crónicas del siglo XVI, como la Relación de las Cosas de Yucatán escrita por el fray Diego de Landa (1959). En estos documentos el personaje aparece como hombre deificado, mito, dios, héroe cultural, fundador de ciudades... Landa lo menciona que fue un gran señor que gobernó Chichén Itzá y que “entró por la parte poniente y que difieren si entró antes o después de los Yzáes, o con ellos”. ${ }^{15}$ Además registró Landa que Kukulcán le puso nombre al sitio de Mayapán. 
Para Cobos, Kukulcán fue un soberano importante de Chichén Itzá quien gobernó el sitio en algún momento del siglo X. ${ }^{16}$ Este investigador cita las Relaciones Histórico-Geográficas de la Gobernación de Yucatán ${ }^{17}$ para justificar su argumento en donde Kukulcán es registrado como gran señor de Chichén Itzá, en tanto que la iconografía asociada con el Templo del Norte o del Hombre Barbado y el Templo del Chacmool parece corroborar esta evidencia ya que muestra la entronización del Capitán Serpiente en Chichén Itzá. Concluye Cobos que después de la muerte del gobernante que llevó por nombre Kukulcán, otros soberanos que gobernaron Chichén Itzá pudieron haber utilizado él término Kukulcán como título asociado a la más alta jerarquía política.

Según Lincoln Kukulcán es un título de los soberanos que gobernaron Chichén Itzá y cuyo icono distintivo es una serpiente emplumada. ${ }^{18}$ Así, el nombre de Kukulcán se asocia con uno de los tres hermanos o primos que gobernaron Chichén Itzá. Cuando alguno de estos hermanos o primos moría o se separaba del poder, Kukulcán asumía el trono de nueva cuenta para evitar caos o incertidumbre. Correspondía a Kukulcán volver a generar el orden social mediante el restablecimiento de un gobierno compartido con sus hermanos o primos. Por lo tanto, durante los ciclos de gobierno, Kukulcán aparece como la figura central que restablece el orden y ésta función lo asocia con el aspecto de sacerdote soberano.

Para Navarro, Kukulcán es una metáfora de la construcción de un nuevo régimen político que culmina con la construcción de la Gran Nivelación de Chichén Itzá. ${ }^{19}$ Este personaje sería el responsable por la edificación de la gran explanada y los edificios construidos fueron erigidos a su honor. La existencia de la iconografía de serpientes emplumadas, el principal símbolo de Kukulcán, en casi todos los edificios de la Gran Nivelación es la evidencia de que este gran señor tuvo en sus manos un poder centralizado.

Por otro lado, las mismas fuentes acerca de este personaje lo refieren como una divinidad. Según López Cogolludo, los yucatecos "veneraban un ídolo de uno, que había sido gran capitán entre ellos, llamándole Kukulcán ...” ${ }^{20} \mathrm{Y}$ Landa dice que después de la partida de Kukulcán "hubo entre los indios algunos que dijeron que se había ido al cielo con los dioses y por eso lo tuvieron por dios y le señalaron templo en que como a tal le celebrasen su fiesta, y se la celebró toda la tierra hasta la destrucción de Mayapán”. ${ }^{21}$

La Relación de Motul relata que los mayas tenían al principio sólo un dios creador, cuya morada era el cielo, "y esta manera de adoración tuvieron hasta que vino de fuera de esta tierra un gran señor con gente llamado Kukulcán ...” Según López Cogolludo "Murió este rey y levantáronle altares, y era oráculo, que les daba respuestas, y allí le edificaron templo. Decían que levantaba los muer- 
tos, que los resucitaba y sanaba los enfermos, y así le tenían gran veneración. Estos indios tenían este crédito, y así no conocían otro Dios autor de la vida, sino a este ídolo; que decían los resucitaba y sanaba”. ${ }^{22}$

Pasaremos ahora a contextualizar el espacio sagrado que pensamos ser concerniente a la divinidad, cuya principal manifestación es la serpiente emplumada.

\section{KUKULCÁN Y SU ESPACIO SAGRADO}

Rapoport considera que el espacio está organizado jerárquicamente, y que es la expresión de las instituciones sociales, de los sistemas, de los grupos y del esquema cognitivo, sugiriendo que es a través de la investigación del contexto específico que se pueden comprender las diferentes maneras en las que está organizado el espacio. La organización del espacio es una expresión del medio ambiente, del paisaje y de la cultura material y es indisociable de los aspectos de la vida humana. La organización del espacio refleja, refuerza y guía la organización de la comunicación. La expresión física de la organización espacial es también un aspecto de la organización del significado pues es un reflejo de la vida social y de los arreglos culturales de un grupo.

Para Renfrew el culto, como un acto de adoración que legitima la religión, implica estructuras de creencias compartidas que son trasferidas a la arquitectura. ${ }^{23}$ Considera que un culto está formalizado, y por lo tanto, necesita de un espacio para manifestarse con una planeación y un esquema específico. A nivel teórico, este autor ofrece algunos indicadores cúlticos con el objetivo de que el arqueólogo pueda inferir su presencia en un determinado sitio arqueológico:

- El culto es realizado en un área específica y posee asociaciones naturales, como un cerro o una caverna.

- El culto es llevado a cabo en construcciones especiales destinadas a las funciones sagradas, como un templo o una iglesia.

- La estructura y el equipamiento usado en el culto revelan un plan previo, y se reflejan en la arquitectura y en sus peculiaridades de construcción como son los altares, escaleras y frisos, y en el equipamiento móvil como son los incensarios, lámparas y toda la parafernalia del culto.

- El área sagrada del culto presenta repetidos símbolos en forma abstracta.

- El área sagrada incluye un espacio dedicado al público, que va a adorar a la divinidad.

- Los símbolos del culto están representados más eficazmente en la iconografía. El simbolismo animal muchas veces puede representar a una divinidad.

- Las tumbas y entierros también pueden delatar la presencia del culto. 
- La adoración a una divinidad puede incluir movimientos especiales como las peregrinaciones, y pueden estar reflejados en la iconografía.

- El sacrificio humano y animal pudo haber sido practicado.

- La ofrenda de objetos votivos pueden ser traídos de otros lugares.

A partir de este modelo, podemos aplicarlo a Chichén Itzá en el sentido de delimitar un espacio sagrado destinado al culto guerrero a Kukulcán. Pensamos que este espacio fue la Gran Terraza o Gran Nivelación.

Chichén Itzá é um dos sítios arqueológicos mais conhecidos da área maia. Como se sabe, os maias desenvolveram uma importante civilização que geograficamente se localizou no sul do México até a porção ocidental das Honduras. O período de esplendor da civilização é conhecido como Clássico, começa no ano 300 d.C. e vai até o ano de 909 d.C. quando a escrita deixa de ser produzida. O Clássico se caracteriza pela construção de grandes cidades, algumas delas com mais de 60 mil habitantes, como Tikal e Calakmul. Este período tem como principais características o emprego da arquitetura monumental, a escrita hieroglífica (a única totalmente fonética entre as civilizações pré-colombianas), o comércio de longa distância e o poder centralizado nas mãos de um governante.

Sabe-se que a partir do século IX a maioria das cidades maias colapsa, por razões ainda bastante discutidas. No entanto, a pressão demográfica, a intensificação da guerra e a degradação do meio ambiente foram fatores essenciais para o declínio dos maias. É durante o colapso maia nas Terras Baixas do Sul que outras cidades, situadas no norte da Península do Iucatã, como Uxmal, Sayil, Labná, Ek Balam e Chichén Itzá alcançam o seu auge.

Com respeito à Chichén Itzá, a cidade alcançou seu esplendor entre os anos de 800 e 1000 d.C., um período conhecido como Clássico Terminal na área maia ou Epiclássico. Chichén Itzá foi a cidade mais importante dessa época. Controlou a rota de sal em toda a área maia, impôs impostos e tributava um grande número de cidades e controlou as rotas marítimas no Caribe e Golfo do México através de seu principal porto, a ilha Cerritos. Chichén Itzá também foi a mais importante rota de peregrinação da área maia, através do Cenote Sagrado, um poço artificial onde eram realizadas oferendas a seus principais deuses: Chaac e Kukulcán.

La Gran Nivelación representa la obra arquitectónica de mayor magnitud en el sitio. Esta construcción consiste en la nivelación de una gran plataforma sobre la cual se localizan los edificios conocidos como El Castillo o Pirámide de Kukulcán, el Gran Juego de Pelota, el Templo del Sur, el Templo del Norte, el Templo Superior e Inferior de los Jaguares, el Tzompantli, la Plataforma de las Águilas y Jaguares, la Plataforma de Venus, el Templo de los Guerreros, el Templo de las Mesas, el Grupo de las Mil Columnas y otras construcciones menores. ${ }^{24}$ 
A partir del modelo propuesto por Renfrew podemos inferir la existencia de un culto que se llevó a cabo en la Gran Nivelación. ${ }^{25}$ En primer lugar está área está ligada por la sacbé $n^{\circ} 1$ al Cenote Sagrado (premisa 1). Según las fuentes históricas el cenote fue un lugar en donde se sacrificaban personas como una de las manifestaciones del culto. De hecho, de las exploraciones que se llevaron a cabo en el cenote ${ }^{26}$ se rescataron huesos, la mayoría de niños y hombres adultos (premisa 9). La evidencia del culto también se manifiesta en las peregrinaciones que relatan las fuentes y su probable ejecución a partir de varios objetos procedentes del Centro de México, Guatemala, Chiapas y principalmente el oro que llegaba de algunas áreas de Centroamérica y Colombia (premisas 8 y 10).

La Gran Nivelación es un espacio que está amurallado. De carácter defensivo o no, esta muralla más bien sirvió para delimitar el espacio del culto y dar cabida a la multitud que participaba de las ceremonias (premisas 3 y 5).

La iconografía de esta área del sitio presenta muchas formas abstractas que todavía no han sido sistemáticamente estudiadas y que pueden presentar relación con el culto, como son las imágenes del planeta Venus y del hombrepájaro-jaguar. Muchas imágenes de animales, como las serpientes emplumadas, los coyotes, jaguares y águilas más bien están relacionadas a la divinidad ya que esta puede representarse en la forma animal (premisas 4 y 6).

\section{EL CULTO GUERRERO A KUKULCÁN}

La principal evidencia del culto guerrero a Kukulcán está en la arquitectura y en la iconografía de la Gran Nivelación. Aunado que la principal manifestación de la divinidad es una serpiente emplumada.

La estructura conocida como El Castillo o Pirámide de Kukulcán es de planta cuadrada, el tipo de sistema constructivo es el talud/tablero y está abovedado. Posee cuatro escalinatas, una de cada lado del edificio. La escalinata norte posee alfardas que están rematadas por serpientes emplumadas. Subiendo la pirámide por esta escalinata, que es la entrada principal, se ubica el templo, cuya entrada está compuesta por columnas de serpientes emplumadas mirando el norte. En las jambas de las pilastras y en la pared del muro del fondo del templo están esculpidos guerreros que portan atlatl (propulsores de dardos), dardos, lanzas, escudos redondos, escudos flexibles, palos defensivo y ofensivo y cuchillos. La escena principal está compuesta por uno de estos guerreros que está envuelto por una serpiente emplumada y parece estar dentro de un óvulo o cartucho (figura 2). A su lado otros guerreros que parecen ser sus prisioneros ya que llevan sogas en las manos. En las jambas de las otras entradas estos guerreros también están representados además de otros que de la misma manera están envueltos por serpientes emplumadas. 


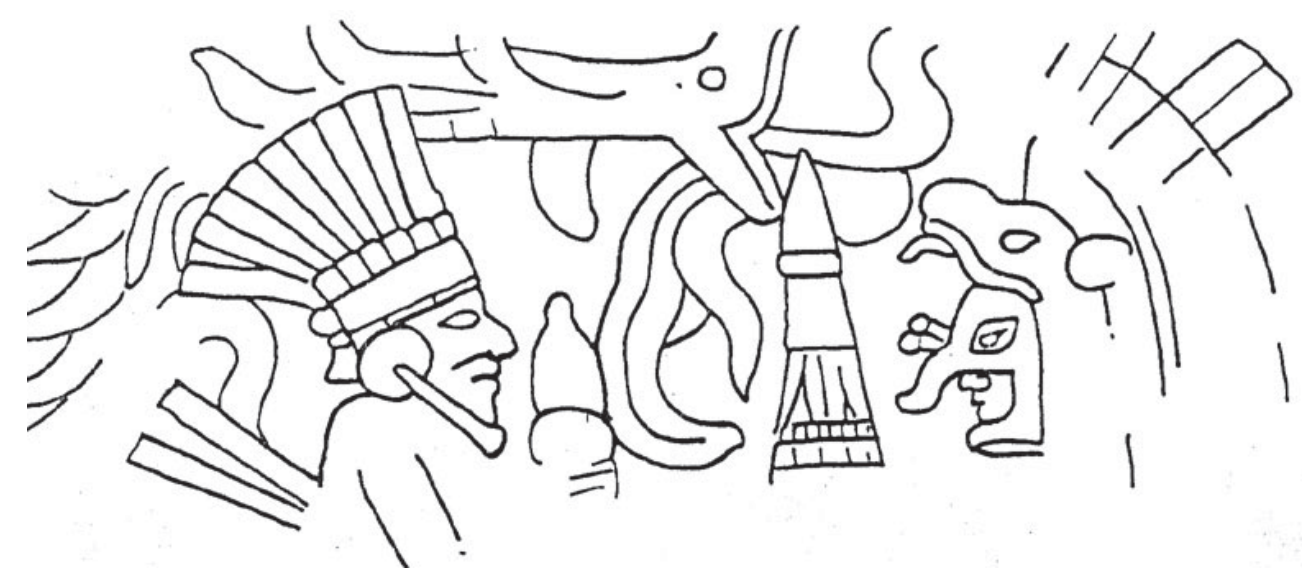

FIGURA 2. Los Capitanes Disco Solar y Serpiente en el dintel del santuario del Castillo. Imagen tomada de Taube).

El Templo del Norte o del Hombre barbado es una estructura de planta rectangular, con sistema constructivo en talud/tablero y está abovedado. Presenta alfardas decoradas el algunos de los elementos decorativos son serpientes emplumadas. El edificio posee columnas en la entrada que la dividen en tres claros. En estas columnas hay representaciones de guerreros portando escudos flexibles, atlatl y dardos y serpientes emplumadas. Las escenas más interesantes están el la pared del muro del fondo y en la decoración de las bóvedas. En general tratase de escenas cotidianas en donde se perciben personas en sus actividades y las chozas de un poblano. Sin embargo hay representaciones de guerreros portando las mismas armas que los de las columnas y están envueltos por serpientes emplumadas. Igual que en El Castillo, hay una escena en donde se ve un personaje guerrero central dentro de un óvulo o cartucho envuelto por una serpiente emplumada y acompañado por otros guerreros. La diferencia es que éstos parecen no ser prisioneros; más bien participan de la entronización de este personaje central.

El Gran Juego de Pelota es una estructura de planta rectangular con sistema constructivo de talud/tablero. Posee alfardas rematadas con cabezas de serpientes emplumadas cuyos cuerpos emplumados corren por todo el friso del edificio. Poseía una escalinata del lado oeste cuyas alfardas también estaban rematadas por serpientes emplumadas y cuyas cabezas se hallan cerca de la estructura en derrumbe. La estructura posee banquetas con paneles decorados en bajorrelieve cuya escena principal parece ser la decapitación de un personaje de cuyo cuello expuesto salen siete serpientes. Algunos de estos personajes también portan un objeto en la mano que tiene la forma de una serpiente. Y de los sombreros de otros salen estas mismas serpientes. 
El Templo Superior de los Jaguares es una estructura de planta cuadrada con sistema constructivo en talud/tablero y está abovedado. El acceso al templo se da por una escalinata que está remata por serpientes emplumadas. Los ángulos del edificio presentan cabezas de estos animales cuyos cuerpos emplumados corren por todo su friso. La entrada del templo está formada por dos columnas de serpientes emplumadas, cada una de ellas pesando cerca de 25 toneladas. Las jambas de la entrada están representados guerreros que portan escudos, atlatl y dardos; algunos de ellos envueltos por serpientes emplumadas. En la parte inferior están esculpidos los hombres-pájaro-jaguar. Los frisos superiores del edificio están decoradas con serpientes emplumadas entrelazadas y procesión de jaguares alternados con escudos, estos muy parecidos a los hallados en la Subestructura de El Castillo. Sin embargo, lo más interesante es que dentro del templo, en sus paredes, fueron pintadas muchas escenas en diversos colores. El tema principal de estas escenas son batallas y enfrentamiento de dos grupos de guerreros. Estos grupos son liderados por un Capitán Disco Solar, ${ }^{27}$ cuyas tropas siempre portan escudos rectangulares; y por un Capitán Serpiente, cuyos guerreros llevan escudos redondos. En todas las escenas de combate parece ser que el Capitán Serpiente siempre es el victorioso. Resulta que este Capitán está representado no solamente por una serpiente, sino por una serpiente emplumada. Las escenas parecen ser la mayor demostración del poderío militar en el área maya. Los guerreros portan todos los tipos de armas y algunas todavía desconocidas en la literatura: atlatl, dardos, cuchillos, escudos redondos, escudos flexibles, palos defensivo y ofensivo y lanzas. Se evidencian también captura de prisioneros que son humillados, capturados, sacrificados, decapitados por el uso de estas armas. Muchas de estas acciones son llevadas a cabo por el Capitán Serpiente que también parece tomar algunas aldeas y destruirlas.

El Tzompantli es una estructura de planta rectangular con sistema constructivo en talud/tablero. Posee una escalinata rematada por serpientes emplumadas y con representación de guerreros. Los ángulos de la estructura, como en el Templo Superior de los Jaguares, está rematado por cabezas de serpientes emplumadas que corren por todo el friso de la estructura. Los tableros están decorados con muchas filas de serpientes emplumadas. Los guerreros esculpidos en bajorrelieve portan atlatl y dardos e llevan en una de manos una cabezatrofeo. La peculiaridad de estos personajes es que todos tiene la pierna descarnada o esquelética, así como algunos de los guerreros representados en el Templo del Sur. En muchos de estos guerreros salen serpientes emplumadas de sus cuerpos, de los dos lados, como se estuvieran envueltos por estos animales. Otra peculiaridad de estos guerreros es que ellos portan las lanzas más grandes encontradas en toda la iconografía de la Gran Nivelación, y del sitio. 
La Plataforma de las Águilas y Jaguares es una estructura cuadrada con sistema constructivo en talud/tablero. Posee cuatro escalinatas cada cual rematada por cabezas de serpientes emplumadas cuyos cuerpos emplumados decoran las alfardas del edificio. Los frisos de la estructura están decorados por personajes recostados a la manera de los chacmooles y llevan un objeto en las manos.

El Templo de Venus es otra estructura de planta cuadrada con sistema constructivo en talud/tablero. Posee cuatro escalinatas cada cual rematada por cabezas de serpientes emplumadas y, diferentemente del Templo de las Águilas y Jaguares, los cuerpos emplumados de estos animales corren por todo el friso de la estructura en vez de decorar las alfardas. En los tableros del edificio hay representaciones del hombre-pájaro-jaguar y el símbolo de Venus que se suele relacionar a la guerra en la literatura maya.

El Templo de los Guerreros es una estructura de planta cuadrada con sistema constructivo en talud/tablero y estuvo abovedado. Posee una escalinata cuyas alfardas están rematadas por cabezas de serpientes emplumadas. Cuenta con banquetas en donde están esculpidos guerreros que portan escudos, atlatl y dardos. Las cornisas de estas banquetas están decoradas con procesión de serpientes emplumadas y, en muchas de ellas, hay guerreros saliendo de sus fauces abiertas. Los tableros del edificio están decorados con el hombre-pájaro-jaguar. La entrada del templo está formada por dos pilastras de serpientes emplumadas, parecidas a las columnas halladas en El Castillo, Templo Superior de los Jaguares y Templo de las Mesas. El templo posee varias pilastras interiores, que posiblemente sostenían el techo, con representaciones de guerreros que portan las mismas armas de los demás encontrados en el edificio. Las jambas de la entrada también están representados estos mismos personajes. En el último cuarto de la estructura hay una banqueta sostenida por talantes en cuyas cornisas están esculpidas serpientes emplumadas en procesión. Cuando la estructura empezó a ser restaurada en los años 1930 por la Carnegie Institution of Washington las paredes del edificio estaban decoradas con pintura mural, que por su estado de conservación no pudieron ser salvas pero fueron dibujadas con fidelidad y una copia de estas escenas se encuentran en el museo del sitio de Chichén Itzá. La mayoría de las pinturas tienen como representación escenas ubicadas en el mar o en regiones lacustre. En una escena peculiar se ven los guerreros portando bolsas en una representación casi idéntica de los representados en las pilastras del Templo del Sur. En esta misma representación, en la parte superior derecha de la pintura, se percibe una persona dentro de un templo rindiendo culto, cuya estructura está ornamentada con una serpiente emplumada.

La Columnata Noreste es un conjunto de planta rectangular de 259 pilastras que se halla frente al Templo de los Guerreros. Su sistema constructivo es el 
talud/tablero y probablemente sostenía bóvedas. Las principales representaciones de estas pilastras son guerreros que llevan diferentes armas, como atlatl, dardos, cuchillos, lanzas, escudos, palos defensivo y ofensivo; en sus cuatro lados. Algunos de estos personajes están envueltos por serpientes emplumadas. Muchos de estos personajes llevan sogas en las manos y parecen ser prisioneros, incluso uno de ellos tiene un cuchillo fincado en el cuello. En la parte inferior de cada una de estas pilastras hay representaciones del hombre-pájaro-jaguar en sus cuatro lados. En las banquetas adosadas al conjunto arquitectónico hay representaciones de guerreros profusamente armados y procesión de serpientes emplumadas decorando sus cornisas. Otras banquetas del mismo estilo pueden encontrarse en la Columnata Norte y en El Mercado.

El Mercado es una estructura rectangular con sistema constructivo en talud/tablero y que posiblemente estuvo abovedado. También es el mejor ejemplo de estructura del tipo patio-galería hallada en el sitio. En la banqueta adosada a la estructura hay representaciones de guerreros que portan atlatl, dardos y lanzas. En el friso principal hay la representación de una procesión de guerreros que llevan sogas en las manos y están sometidos a un personaje central que está envuelto por una serpiente emplumada. Esta escena es parecida con la de la pared del muro del fondo de la entrada norte de El Castillo. En las jambas de la entrada de la estructura hay representaciones de guerreros que llevan las mismas armas de los demás encontradas en el edificio.

Para concluir esta sección, aclaramos que del cenote sagrado, asociado a la Gran Nivelación a través del sacbé 1, se recuperaron muchos artefactos en representaciones de guerreros y serpientes emplumadas. De los ocho discos de oro recogidos, muchos de ellos tienen representación de guerreros armados idénticos a los encontrados en la iconografía de los edificios de la Gran Nivelación. Y en muchas de estas escenas hay representaciones de serpientes emplumadas también en el mismo estilo de las halladas en la extensión de toda la Gran Terraza. Otros artefactos recogidos son placas de jade, cuentas y cerámica, también con representación de guerreros y serpientes emplumadas.

\section{DISCUSIÓN Y CONSIDERACIONES FINALES}

Es sabido que las escenas de conflicto dominan el arte de Chichén Itzá. ${ }^{28}$ Estos conflictos han recibido una especial atención por muchos investigadores, y sus conclusiones son muy dispares. Desde las acepciones de Tozzer ${ }^{29}$ hasta investigaciones más recientes se ha creído que Chichén Itzá tiene monumentos conmemorativos de la invasión tolteca ocurrida en el siglo X. Los decisivos escritos de Tozzer hicieron que se aceptara ampliamente el concepto de invasión durante el mencionado siglo. En su detallada cronología de invasiones, migraciones 
y otros incidentes en la historia maya tuvo como fuentes documentos de origen nativo escritos en frases de difícil interpretación que fueron compilados siglos después de que supuestamente acontecieron tales sucesos. ${ }^{30}$

En este sentido, la visión tradicional de la historia maya vincula el conflicto, el sacrificio humano y la glorificación de la guerra en la iconografía, a la llegada de personas e ideas procedentes del centro de México durante el Posclásico. Las ruinas de Tula se consideran la patria original de los toltecas, quienes invadieron Chichén Itzá, pero la alfarería y la arquitectura en ambos sitios es distinta. La cerámica y técnicas de construcción en ambos lugares tiene sus raíces en tradiciones arqueológicas locales.

La iconografía de Chichén Itzá se diferencia claramente de otros lugares de Yucatán y puede ser considerada como un estilo local a pesar de algunas características originadas en el centro de México. Luego, gran parte de las ideas y sus representaciones iconográficas llegaron a la península por medio del tráfico comercial que prosperó a lo largo de la costa. Andrews y Gallareta Negrón han esclarecido el mecanismo con el cual ideas, materiales y gente pasaron al área de Chichén Itzá. ${ }^{31}$ En sus excavaciones en la Isla Cerritos cerca de la costa norte de Yucatán, encontraron materiales extraños en abundancia. La isla sirvió como base para el comercio marítimo. La Isla Cerritos parece haber sido el puerto principal para Chichén Itzá. De esta manera, el tráfico comercial trajo ideas extrañas, mercaderías y nuevos conceptos que se fundieron con las formas de representación iconográfica de los indígenas para crear la mezcla que se puede observar en Chichén Itzá.

Estos conflictos representados en la iconografía de Chichén Itzá nos llevan a creer que este fenómeno se intensificó entre los asentamientos durante el Clásico Tardío y Terminal (600-1000 d.C.). Estos rasgos pueden ser identificados arqueológicamente. Se puede percibir fortificaciones, murallas defensivas y albarradas cercando los edificios en varios de los sitios de este periodo, como en Muna, Cobá y Chunchucmil. En Chichén Itzá hay varios espacios amurallados. Datos relacionados con los patrones de asentamiento sugieren que el incremento demográfico llegó a su apogeo en el periodo mencionado. Luego, es de esperar, entre poblaciones densas, que se incrementen los conflictos.

Ya según Robertson y Andrews la iconografía de Chichén Itzá ofrece la evidencia de un enorme conflicto, una lucha interna por el poder. ${ }^{32}$ Basándose en las similitudes de la iconografía su trabajo muestra la coexistencia entre grupos sociales, probablemente familias, representando facciones competidoras. Piensan las investigadoras que el plan concebido en la colocación específica de las pilastras en la Columnata Noroeste, así como los dinteles de madera labrados del Castillo, señalan un gran conflicto interno en Chichén Itzá durante su periodo 
floreciente. Al estudiar las los diferentes personajes retratados en estas pilastras, como sacerdotes, guerreros y prisioneros las investigadoras concluyen que se puede apreciar los distintos grupos étnicos representados en todos los niveles en un tiempo de gran conflicto interno.

Sin embargo discordamos de los autores presentados que este conflicto haya desestructurado la organización social del centro urbano. Al revés, la disposición de las estructuras en el espacio y la simetría de las representaciones iconográficas y arquitectónicas de los edificios nos hacen creer que hubo una organización social interna muy organizada para ordenar estas acomodaciones, que serían imposibles de la manera que Kurjack y Robertson y Andrews conciben tal conflicto interno. ${ }^{33}$

Más que un reflejo del conflicto interno en Chichén Itzá pensamos que la iconografía del sitio tiene un fuerte mensaje de un culto guerrero centrado en la divinidad Kukulcán, independientemente de cual sea la naturaleza de esta guerra. Los estudiosos han basado sus modelos de conflicto interno a partir de las imágenes de guerreros ampliamente representadas en la extensión del sitio. Sin embargo olvidan decir que muchos de estos guerreros están acompañados de serpientes emplumadas en diferentes contextos.

En su interesante trabajo Robertson y Andrews en la Columnata Noroeste y en el Templo del Chacmool que sirvieron de base para su modelo de conflicto interno en el sitio, dejan de citar que muchos de estos guerreros son caracterizados por serpientes emplumadas. En algunas de las pilastras estos animales envuelven los guerreros. Además en la banqueta adosada a la estructura hay serpientes emplumadas en las cornisas, además de guerreros de salen de dentro de las fauces abiertas de estos reptiles. Escenas de guerreros y serpientes emplumadas también son encontradas en el Templo del Chacmool. En una de las paredes de esta estructura, en toda su extensión, había la pintura de una gran serpiente emplumada que hoy ya se ha borrada. Una reproducción de esta pintura puede verse en el museo del sitio de Chichén Itzá.

Los rasgos compartidos de estos guerreros en cuanto su indumentaria y armas pueden encontrarse en toda la extensión de la Gran Nivelación, en lo que se percibe un plan muy bien ejecutado por sus idealizadores. Guerreros portando atlatl, escudos y dardos son representados de manera similar en el Castillo, en los Templos Superior y Inferior de los Jaguares, en los Templos del Norte y Sur, en el Gran Juego de Pelota y en el Templo de las Mesas. En algunas de estas estructuras hay pilastras y columnas con representaciones de serpientes emplumadas planeadas en el mismo estilo y gran similitud. Las procesiones de guerreros pueden apreciarse en estructuras como El Castillo, Templo de los Guerreros y El Mercado. Interesante también notar que estas representaciones de guerreros están en es- 
tructuras que poseen rasgos arquitectónicos equivalentes, es decir, poseen alfardas, sistema constructivo en talud/tablero, crujías y techo abovedados.

Como hemos mencionado, el culto se manifiesta en espacios específicos. El espacio comprende y expresa ciertos principios de orden y clasificación. Como un medio cultural construido, el espacio es un contexto definido en el cual las personas realizan actividades específicas en tiempos específicos. Los medios ocupados son pensados antes de ser construidos. Y ese medio existe en términos de nuestras acciones y significados. El espacio arquitectónico puede ser definido como la concretización del espacio existencial, es decir, los elementos del paisaje son construidos culturalmente y transformados dentro de sus marcadores materiales y permanentes autenticando la historia, la experiencia, por extensión, la cultura de un grupo. ${ }^{34}$

A manera de conclusión, sugerimos que la iconografía del sitio de Chichén Itzá; la similitud entre los personajes esculpidos en bajorrelieve, en general guerreros; la profusa representación de estos individuos junto de serpientes emplumadas, que es la manifestación más común de la divinidad Kukulcán; la disposición de la Gran Nivelación que presenta un espacio muy organizado y está amurallado; la simetría de los rasgos arquitectónicos de los edificios de esta plaza, como las columnas y pilastras de serpientes emplumadas y bóvedas decoradas son evidencia de un espacio estructurado, ordenado y muy bien organizado en donde se celebraban el culto a Kukulcán bajo su manifestación guerrera, más bien que un espacio que refleja un gran conflicto interno en Chichén Itzá.

\section{NOTAS}

2 DICCIONARIO MAYA CALEPINO DE MUTUL. Diccionario maya-español. TOMO III, Ramón Arzápalo Marín (organizador). México D.F.: UNAM, 1995, p. 1843

3 Idem.

${ }^{4}$ Idem, Ibidem, p. 1846.

${ }^{5}$ Idem, Ibidem, p. 1535.

${ }^{6}$ DICCIONARIO CAKCHIQUEL-ESPAÑOL. Carmelo Sáenz de Santa María (recopilador). Guatemala, 1940.

7 DICCIONARIO MAYA CORDEMEX. Alfredo Barrera Vázquez (director). Mérida: Ediciones Cordemex, 1980.

${ }^{8}$ Idem, Ibidem, pp. 420-42I.

${ }^{9}$ Idem.

${ }^{10}$ Idem, Ibidem, p. 374.

"Idem, Ibidem, p. 420.

${ }^{12}$ Idem.

${ }^{13}$ LINCOLN, Charles. Structural and Philological Evidence for Divine Kinship at Chichén Itzá, Yucatán, México. Berlin, 1994.

14 Idem, Ibiden, p. 179. 


\section{REVISTA ESBOÇOS Volume 16, № 22, pp. 111-126 - UFSC}

${ }^{15}$ LANDA, Fray Diego de. Relación de las Cosas de Yucatán. México: Editorial Porrúa, 1959, p. 13.

${ }^{16}$ COBOS, Rafael. "Fuentes históricas y arqueología: convergencias y divergencias en la reconstrucción del periodo Clásico Terminal de Chichén Itzá". En: Mayab, Sociedad Española de Estudios Mayas, nº 12. Madrid: Universidad Complutense de Madrid, 1999, p. 58-70.

${ }^{17}$ DE LA GARZA, Mercedes. Relaciones Histórico-Geográficas de la Gobernación de Yucatán. México: Instituto de Investigaciones Filológicas, Centro de Estudios Mayas, UNAM, 1983.

${ }^{18}$ LINCOLN, Charles E. Ethnicity and Social Organization at Chichén Itzá. Tesis de Doctorado. Cambridge: Harvard University, 1990.

19 NAVARRO, Alexandre Guida. Las serpientes emplumadas de Chichén Itzá: distribución en los espacios arquitectónicos e imaginería. Tesis de Doctorado. México: UNAM, 2007; NAVARRO, Alexandre Guida. O Retorno de Quetzalcóatl: contribuiçao ao conhecimento do culto a divindade a partir do registro arqueológico de Chichén Itzá, México. Sao Paulo: tesis de maestría, Facultad de Filosofía y Letras, Museo de Arqueología y Etnología de la Universidad de São Paulo, 2002.

${ }^{20}$ LÓPEZ COGOLLUDO, Diego. Los tres siglos de la dominación española en Yucatán, o sea Historia de esta provincia, 2 vols., Akademische Druck u. Verlagsanstalt, Graz, Austria, 197I.

${ }^{21}$ LANDA, cit. p. 98.

22 LÓPEZ COGOLLUDO, cit.

${ }^{23}$ RENFREW, Colin. The Archaeology of Cult. Londres: Thames and Hudson, 1985.

${ }^{24}$ Piña Chán, Román. Chichén Itzá: la ciudad de los brujos del agua. México: Fondo de Cultura Económica, 1980; Peter. Proyecto Chichén Itzá. Mecanoescrito. México: CRY-INAH, 1992; Cobos, cit. 1999; Navarro 2002, 2007).

${ }^{25}$ RENFREW, C. cit.

${ }^{26}$ THOMPSON, Edward H. "Archaeological Research in Yucatán". En: Memories del Peabody Museum Harvard University, vol. I, n 3, Cambridge, Massachusetts, 1904. PIÑA CHÁN, Román. "Informe Preliminar de la Reciente Exploración del Cenote Sagrado de Chichén Itzá". En: Serie de Investigaciones, n² 24. México: INAH, 1970.

27 MILLER, Arthur G. "Capitanes del itzá: evidencia mural inédita de Chichén Itzá". En: Estudios de Cultura Maya no II. México: 1978, p. I21-154.

${ }^{28}$ KURJACK, Edward B. "Conflicto en el arte de Chichén Itzá". En: Mayab, Sociedad Española de Estudios Mayas n 8. Madrid: Universidad Complutense de Madrid, 1992, p. 88-96.

29 TOZZER, Alfred M. "Maya and Toltec Figures at Chichén Itzá". En: Twenty third International Congress of Americanists, Acta, Nueva York, 1930, p. I55-164. TOZZER, Alfred M. Chichén Itzá and Its Cenote of Sacrifice: a Comparative Study of Contemporaneous Maya and Toltec. Washington: Memoirs of the Peabody Museum of American Archaeology and Ethnology, 1957.

30 KURJACK, cit.

${ }^{31}$ ANDREWS, Anthony P. \& GALLARETA NEGRÓN, Tomás. "The Isla Cerritos Archaeological Project, Yucatán, México". En: Mexicon, vol. 8, n 3. México, 1986, p. 44-48.

32 ROBERTSON, Merle Greene \& ANDREWS, Margaret. "Una evaluación del arte del Templo del Chacmool y de la Columnata Noroeste en Chichén Itzá: coexistencia y conflicto interior". En: Mayab , Sociedad Española de Estudios Mayas, nº 8. Madrid: Universidad Complutense de Madrid, 1992, p. 54-87.

33 KURJACK, Edward B. cit.. ROBERTSON, Merle Greene \& ANDREWS, Margaret, cit.

${ }^{34}$ PEARSON, Mike Parker; RICHARDS, Colin. "Ordering the World: Perceptions of Architecture, Space and Time". En: Architecture and Order, Mike P. Pearson y Colin Richards (eds.). Londres: Routledge, 1994, p. I-37. 